
\title{
25 Research Soure \\ Stroke Risk Factors, Subtypes and Outcome in Elderly Thai Patients
}

\section{Chatpol Samuthpongtorn}

Faculty of Medicine, Chulalongkorn University Bangkok

\section{Tul Jereerat}

Faculty of Medicine, Chulalongkorn University Bangkok

Nijasri Suwanwela ( $D$ nijasris@yahoo.com )

Division of Neurology, Department of Medicine, Chulalongkorn Comprehensive Stroke Center, King Chulalongkorn Memorial Hospital, Bangkok

\section{Research Article}

Keywords: Stroke, Outcomes, Risk factors, Stroke classification, Elderly, Thailand

Posted Date: January 13th, 2021

DOl: https://doi.org/10.21203/rs.3.rs-140400/v1

License: (c) (i) This work is licensed under a Creative Commons Attribution 4.0 International License. Read Full License

Version of Record: A version of this preprint was published at BMC Neurology on August 20th, 2021. See the published version at https://doi.org/10.1186/s12883-021-02353-y. 


\section{Abstract}

Background: Nowadays, the number of elderly has steadily increased annually. Elderly patients with ischemic stroke often have worse outcomes than younger patients. However, there has not been a study of ischemic stroke in the elderly in Thailand. A better knowledge of the risk factors, subtypes, and outcomes of strokes in the elderly may have significant practical implications for the aged society in the future. The objective of the study was to assess the risk factor, stroke subtypes, and outcome of stroke in the elderly compared to the younger patients.

Method: All patients presented with acute ischemic stroke and transient ischemic attack (TIA) aged over 45 years who were admitted in the Stroke unit between November 1st, 2016 and December 31st, 2017 were retrospectively studied.

Result: 542 patients were included. The average age was $68.78 \pm 12.03,44.8 \%$ of them were male. 186 (34.3\%) patients were 75 or older. Cardioembolism was found to be the most common cause of ischemic stroke in 156 patients $(28.8 \%)$. Patients who were 75 or older had significantly worse outcomes in all categories including NIHSS at discharge, modified Rankin scale, length of stay and the number of deaths) compared to the younger group. Atrial fibrillation was the risk factors associated with older age with OR 3.861 ( $p$ value $<0.001$ ). Aged 75 years or older, atrial fibrillation, more NIHSS score on admission and history of the previous stroke were the risk factors associated with a patient's death.

Conclusion: The elderly who are 75 years or older accounts for more than one-third of ischemic stroke in our study. Stroke in the elderly correlates with higher mortality and poorer outcome. Cardioembolism related to atrial fibrillation is the major cause of stroke in this population.

\section{Introduction}

Stroke is one of the leading causes of death and disability in Thailand. The incidence of strokes in Thailand has been increasing annually. The number of new stroke cases are approximately 250,000 cases and accounts for more than 50,000 deaths each year. The prevalence of stroke is estimated to be $1.88 \%$ among adults 45 years and older (1). It carries the highest rank for disease burden in Thailand measured by disability-adjusted life years (DALYs) lost in females and the third in males (2).

Nowadays, an aging phenomenon is one of the most important global challenges. The number of the elderly has steadily increased and it is expected that Thailand will be faced with an aged society of which more than $20 \%$ of the population will be older than 60 in $2021(3,4)$.

Major risk factors of stroke include age, ethnicity, hypertension, diabetes mellitus, smoking, metabolic syndrome and atrial fibrillation. There are many subtypes of stroke and some subtypes are highly related to age, for example, atherosclerosis, atrial fibrillation and small vessel disease $(5,6,7)$. Moreover, elderly patients with ischemic stroke often have worse outcomes than younger patients $(8,9)$. Ischemic stroke has not been investigated in the elderly in Thailand. Hence, a better knowledge of the risk factors, 
subtypes and outcome of strokes in the elderly may have significant practical implications for early detection, stroke prevention and clinical management for the aged society in the future. The objective of the study was to assess the risk factors, stroke subtypes and outcome of stroke in the elderly compared to the younger patients.

\section{Method}

All patients presented with acute ischemic stroke and transient ischemic attack (TIA), aged over 45 years who were admitted to the Stroke unit, King Chulalongkorn Memorial Hospital between November 1st, 2016, and December 31st, 2017, were retrospectively reviewed. Patients with hemorrhagic stroke and cerebral venous thrombosis were excluded. Ischemic stroke was diagnosed by clinical history, physical examination and confirmed by neuroimaging. TIA was defined as any focal cerebral ischemic event with symptoms lasting less than 24 hours. Electronic medical records and neuroimaging studies were reviewed. Clinical parameters considered were age, sex, vascular risk factors, associated comorbidity, stroke etiology and functional outcome. Data on TOAST classification, NIHSS score and Modified-Rankin scale were also collected All of the data were evaluated by neurologists at the Stroke Unit. Based on the TOAST criteria, ischemic stroke was classified into 5 categories: large-artery atherosclerosis, cardioembolism, lacunar infarction, other determined and undetermined etiologies. The study was approved by the Institutional Review Board of the Faculty of Medicine, Chulalongkorn University (IRB 037/63).

\section{Ethics}

This study met the criteria of Expedited review from International Ethical Guidelines for health-related research Involving Human 2016 [20]. The chart reviews were gathered for information on a specific medical condition and set of patient characteristics. The data was kept anonymous without name or contact of the participant.

\section{Statistical analysis}

Statistical Package for the Social Science for Windows Version 21(SPSS 21) was used for all analyses. Categorical data were presented as number and percentage. Continuous variables were expressed as mean + /- standard deviation. Categorical data were analyzed by the chi-square test. The Mann-Whitney $U$ test was used to compare the continuous variables. Multivariate logistic regression analysis was performed between independent variables that were considered to be associated with stroke subtypes. $P$ value less or equal to 0.05 was considered to be statistically significant.

\section{Results}


There were 542 patients in the study. Fifty-four (9.96\%) presented with TIA, and 488 (90.04\%) had ischemic stroke. The average age of the patients was $68.78 \pm 12.03$ of which $44.8 \%$ were male. There were $186(34.3 \%)$ patients who were 75 or older. The most common risk factor was hypertension, followed by dyslipidemia and diabetes mellitus. Baseline characteristics of the patients are shown in Table 1. 
Table 1

Characteristics of patients stratified by age.

\begin{tabular}{|c|c|c|c|c|}
\hline \multirow[t]{2}{*}{ Characteristic } & $\begin{array}{l}\text { Patients aged } 45- \\
74 \text { years }\end{array}$ & $\begin{array}{l}\text { Patients aged } \geq \\
75 \text { years }\end{array}$ & Total & \multirow[t]{2}{*}{$\begin{array}{l}\mathrm{p}- \\
\text { value }\end{array}$} \\
\hline & $\mathrm{n}=356$ & $n=186$ & $\mathrm{n}=542$ & \\
\hline Male: n (\%) & $144(40.4 \%)$ & 99 (53.2\%) & $\begin{array}{l}243 \\
(44.8 \%)\end{array}$ & 0.005 \\
\hline TIA: n (\%) & $34(63 \%)$ & $20(37 \%)$ & $54(9.96 \%)$ & 0.657 \\
\hline \multicolumn{5}{|l|}{ Risk factors: n (\%) } \\
\hline History of diabetes mellitus & $124(34.8 \%)$ & $76(40.9 \%)$ & $\begin{array}{l}200 \\
(36.9 \%)\end{array}$ & 0.167 \\
\hline History of hypertension & $248(69.7 \%)$ & $150(80.6 \%)$ & $\begin{array}{l}398 \\
(73.4 \%)\end{array}$ & 0.006 \\
\hline History of dyslipidemia & $203(57.0 \%)$ & $113(60.8 \%)$ & $\begin{array}{l}316 \\
(58.3 \%)\end{array}$ & 0.403 \\
\hline Atrial fibrillation & $51(14.3 \%)$ & $72(38.7 \%)$ & $\begin{array}{l}123 \\
(22.7 \%)\end{array}$ & $\begin{array}{l}< \\
0.001\end{array}$ \\
\hline Smoking & $27(7.6 \%)$ & $5(2.7 \%)$ & $32(5.9 \%)$ & 0.022 \\
\hline Previous stroke & $63(17.7 \%)$ & $50(26.9 \%)$ & $\begin{array}{l}113 \\
(20.8 \%)\end{array}$ & 0.012 \\
\hline Previous TIA & $11(3.1 \%)$ & $3(1.6 \%)$ & $14(2.6 \%)$ & 0.301 \\
\hline Previous MI & $31(8.7 \%)$ & $23(12.4 \%)$ & $54(10.0 \%)$ & 0.177 \\
\hline $\begin{array}{l}\text { NIHSS on admission } \\
(\text { mean } \pm \text { SD })\end{array}$ & $6.36 \pm 0.33$ & $7.20 \pm 0.57$ & $6.65 \pm 0.29$ & 0.745 \\
\hline \multicolumn{5}{|l|}{ Stroke subtype: n (\%) } \\
\hline Large artery atherosclerosis & $100(28.1 \%)$ & $30(16.1 \%)$ & $130(24.0 \%)$ & 0.005 \\
\hline Cardioembolism & $75(21.1 \%)$ & $81(43.5 \%)$ & $\begin{array}{l}155 \\
(28.8 \%)\end{array}$ & $\begin{array}{l}<.001 \\
0.001\end{array}$ \\
\hline Small vessel occlusion & $108(30.3 \%)$ & $41(22.0 \%)$ & $149(27.5 \%)$ & 0.085 \\
\hline Other determined & $7(2.0 \%)$ & $1(0.5 \%)$ & $8(1.5 \%)$ & 0.498 \\
\hline Undetermined & $66(18.5 \%)$ & $33(17.5 \%)$ & 99(18.3\%) & 0.859 \\
\hline
\end{tabular}

According to the TOAST classification, cardioembolism was found to be the most common cause of ischemic stroke in 156 patients (28.8\%), followed by small vessel disease in 149 patients (27.5\%), and large vessel atherosclerosis in 130 (24.0\%). 
There were significantly higher percentages of hypertension and atrial fibrillation among patients who were 75 or older. Eighty one patients $(43.5 \%)$ had cardioembolism which was the most common subtype of ischemic stroke followed by small vessel disease in 41 patients $(22.0 \%)$.

Stroke outcomes were described by NIHSS at discharge, modified Rankin scale, length of hospital stay and the number of deaths. Patients who were 75 and older had significantly worse outcomes for all categories compared to the younger age group (Table 2).

Table 2

Outcomes of patients at discharged.

\begin{tabular}{|c|c|c|c|}
\hline \multirow[t]{2}{*}{ Outcome } & $\begin{array}{l}\text { Patients aged } 45- \\
74 \text { years }\end{array}$ & $\begin{array}{l}\text { Patients aged } \geq \\
75 \text { years }\end{array}$ & \multirow[t]{2}{*}{$\begin{array}{l}\text { p- } \\
\text { value }\end{array}$} \\
\hline & $\mathrm{n}=356$ & $n=186$ & \\
\hline NIHSS at discharge (mean \pm SD) & $3.44 \pm 0.268$ & $3.86 \pm 0.476$ & $\begin{array}{l}< \\
0.001\end{array}$ \\
\hline Modified Rankin Scale (mean \pm SD) & $1.92 \pm 0.100$ & $2.16 \pm 0.144$ & $\begin{array}{l}< \\
0.001\end{array}$ \\
\hline $\begin{array}{l}\text { Length of hospital stay: day (mean } \pm \\
\text { SD) }\end{array}$ & $6.919 \pm 0.430$ & $8.427 \pm 0.893$ & $\stackrel{<}{0.001}$ \\
\hline Death: n (\%) & $7(2.0 \%)$ & $14(7.5 \%)$ & 0.001 \\
\hline
\end{tabular}

In the multivariate analysis, the stroke risk factor associated with patients aged $45-74$ years and older age was atrial fibrillation. For the older age group, the OR for atrial fibrillation was 3.861 ( $p$ value $<0.001$ ) (Table 3). 
Table 3

Multivariate analysis for risk factors associated with patients aged $45-74$ years and older.

\begin{tabular}{|lllll|}
\hline & \multicolumn{2}{l}{ Patients aged 45-74 years } & \multicolumn{2}{l|}{ Patients aged $\geq 75$ years } \\
\hline & P values & Odds ratio & P values & Odds ratio \\
\hline sex & 0.408 & 1.153 & 0.056 & 1.459 \\
\hline History of diabetes mellitus & 0.833 & 0.958 & 0.592 & 1.12 \\
\hline History of hypertension & 0.023 & 1.571 & 0.134 & 1.462 \\
\hline History of dyslipidemia & 0.071 & 1.421 & 0.797 & 1.057 \\
\hline Atrial fibrillation & $<0.001$ & 0.393 & 0 & 3.861 \\
\hline Smoking & 0.005 & 3.991 & 0.3 & 0.581 \\
\hline Previous stroke & 0.47 & 0.85 & 0.08 & 1.504 \\
\hline Previous TIA & 0.197 & 2.357 & 0.668 & 0.747 \\
\hline Previous MI & 0.698 & 0.889 & 0.343 & 1.347 \\
\hline
\end{tabular}

Twenty-one patients died during hospitalization. Among these, 14 patients $(66.7 \%)$ were 75 years and older. Risk factors that were associated with death were aged 75 years and older, atrial fibrillation, high NIHSS score upon hospital admission, and history of previous stroke (Table 4). 
Table 4

Factors associated with death during hospitalization.

\begin{tabular}{|llll|}
\hline Factor & Survive & Death & \multirow{2}{*}{ p-value } \\
\cline { 2 - 3 } & $\mathrm{n}=\mathbf{5 2 1}$ & $\mathrm{n}=\mathbf{2 1}$ & \\
\hline Age $\geq 75: \mathrm{n}(\%)$ & $172(33.0 \%)$ & $14(66.7 \%)$ & 0.001 \\
\hline Male: $\mathrm{n}(\%)$ & $231(44.3 \%)$ & $12(57.1 \%)$ & 0.247 \\
\hline Risk factor: $\mathrm{n}(\%)$ & & & \\
\hline History of diabetes mellitus & $193(37.0 \%)$ & $7(33.3 \%)$ & 0.73 \\
\hline History of hypertension & $381(73.1 \%)$ & $17(81.0 \%)$ & 0.426 \\
\hline History of dyslipidemia & $307(58.9 \%)$ & $9(42.9 \%)$ & 0.143 \\
\hline Atrial fibrillation & $111(21.3 \%)$ & $12(57.1 \%)$ & $<0.001$ \\
\hline Smoking & $32(6.1 \%)$ & $0(0.0 \%)$ & 0.242 \\
\hline Previous stroke & $105(20.2 \%)$ & $8(38.1 \%)$ & 0.047 \\
\hline Previous TIA & $13(2.5 \%)$ & $1(4.8 \%)$ & 0.522 \\
\hline Previous Ml & $50(9.6 \%)$ & $4(19.0 \%)$ & 0.156 \\
\hline NIHSS on admission (mean \pm SD) & $6.301 \pm 0.284$ & $14.789 \pm 1.770$ & $<0.001$ \\
\hline Stroke subtype: $\mathrm{n}(\%)$ & & & 0.788 \\
\hline Large artery atherosclerosis & $127(24.4 \%)$ & $3(14.3 \%)$ & 0.602 \\
\hline Cardioembolism & $144(27.6 \%)$ & $12(57.1 \%)$ & 0.002 \\
\hline Small vessel occlusion & $148(28.4 \%)$ & $1(4.8 \%)$ & 0.021 \\
\hline Other determined & $7(1.3 \%)$ & $1(4.8 \%)$ & 0.652 \\
\hline Undetermined & $95(18.2 \%)$ & $4(19.0 \%)$ & $0.78 \%$ \\
\hline
\end{tabular}

\section{Discussion}

We retrospectively studied the risk factors, subtypes, and outcome of ischemic stroke in a single tertiary care center in Thailand. The mean age of our patients was 68.8 years, and $34.3 \%$ were 75 years and older. The proportion of elderly in this study is consistent with the data of general Thai population where $38.7 \%$ were elderly (10). According to the national stroke data, $31.0 \%$ of stroke patients were over 75 years old (11). The prevalence of elderly stroke patients varied among countries and studied population. A study of France found that $28 \%$ of stroke patients were elderly (12) and the absolute number of first-ever strokes increased by $47 \%$ in the patients over 75 years old (12). Another hospital-based prospective study conducted in China found that $22 \%$ of the patients were over 75 years old (13) whereas a multicenter 
study conducted in Mexico showed that approximately $40 \%$ of stroke patients were older than 75 years (14).

Among the elderly stroke patients, hypertension and atrial fibrillation were the 2 most prominent risk factors. Hypertension was the most prevalent risk factor and documented in $73.4 \%$ of total patients in the entire cohort. This risk factor was also noted to be prevalent in many Asian studies including studies from northern China and Southeast Asia. $(15,16)$ Our study found that $38.7 \%$ of the elderly patients had atrial fibrillation compared to only $14.3 \%$ in younger patients. This correlated well with the stroke subtype of which the majority of the elderly patients had cardioembolism. Atrial fibrillation is strongly associated with increased age which was similar to findings reported by other studies $(10,17,18$,$) .$

The most common subtype of ischemic stroke among the elderly in this study was cardioembolism which accounted for more than $40 \%$ of the cases. Atrial fibrillation was responsible for most of them. In contrast, cardioembolic stroke was responsible for only $20 \%$ of those who were younger than 75 years old. This high prevalence of atrial fibrillation may be partly related to the high rate of EKG monitoring among our stroke patients in the stroke unit. EKG monitoring is routinely performed for at least 24 hours in all stroke cases in our institution. Moreover, in those who had clinical suspicion of cardioembolic stroke, Holter monitoring was recommended for further evaluation. Alternatively, large artery atherosclerosis was relatively more common in the younger patients. In both age groups, the proportion of small vessel occlusion was not significantly different.

Regarding the outcomes, patients aged 75 years and older had 2.5 times higher mortality rate and poorer outcome than patients aged below 75 years which is consistent with previous studies $(19)$. The discharged NIHSS scores, mRS, and length of hospital stay were also significantly higher among the elderly. These unfavorable outcomes may be related to a greater severity of stroke among the elderly as measured by the initial NIHSS scores. Moreover, the elderly patients tended to have a higher prevalence of risk factors as well as other comorbidities such as atrial fibrillation and previous stroke. We also observed that cardioembolism was the major cause of stroke in the elderly and this stroke subtype was associated with a poor outcome. Previous studies also demonstrated that patients with cardioembolic stroke had a higher mortality rate and worse outcome (13).

Our study highlighted the importance of stroke among the elderly as we are entering ageing society $(3,4)$. In this study, we used the age of 75 years as the cut-off point which is in line with other recent studies that focused on the treatment of the very old population $(10,12)$. Hypertension was the most common risk factor and cardioembolic stroke was the most common stroke subtype in the elderly and was associated with poor outcome. Thus, it is very important to detect atrial fibrillation among the elderly in order to secondary prevent stroke and manage the patient appropriately.

This study had some limitations. Some confounding factors may not be fully evaluated due to the retrospective nature of the study. Second, although EKG monitoring was performed in all of the patients, however, further evaluation by Holter monitoring were only done in suspected patients. Therefore, it is possible that the number of patients who had atrial fibrillation may have been underestimated. 


\section{Conclusion}

Elderly who were 75 years and older accounted for more than one-third of ischemic stroke patients in our study. Stroke in the elderly correlated with higher mortality and poorer outcome. Cardioembolism related to atrial fibrillation was the major cause of stroke in this population.

\section{Abbreviations}

CT: computed tomography

EKG: Electrocardiogram

mRS: modified Rankin Scale

NIHSS: National Institute of Health Stroke Scale

SD: standard deviation

TOAST: Trial of Org 10,172 in Acute Stroke Treatment

\section{Declarations}

\section{Acknowledgement}

Not applicable

\section{Author contribution}

CS and NCS developed the main conceptual idea and design of the manuscript. CS and TJ collected data, analyzed data and wrote the manuscript. NCS supervised, critically reviewed and edited the manuscript. CS, TJ, and NCS approved the final version of the manuscript.

\section{Author disclosure}

Role of Funding source : Nothing declared

Conflict of interest : No conflict declared

\section{Ethic approval and consent to participate}

The study was approved by the Institutional Review Board of the Faculty of Medicine, Chulalongkorn University (IRB 037/63). According to the Institutional Review Board of the Faculty of Medicine, 


\section{Consent for publication}

Not applicable

\section{Availability of data and material}

The datasets are available from the corresponding author on reasonable request.

\section{Competing interests}

The authors declare that they have no competing interests

\section{Funding}

No funding received

\section{References}

1. Suwanwela N. Stroke Epidemiology in Thailand. Journal of Stroke. 2014;16(1):1.

2. Bundhamcharoen $\mathrm{K}$, Odton P, Phulkerd S, Tangcharoensath- ien V. Burden of disease in Thailand: changes in health gap be- tween 1999 and 2004. BMC Public Health 2011;11:53.

3. Srichuae S, Nitivattananon V, Perera R. Aging society in Bangkok and the factors affecting mobility of elderly in urban public spaces and transportation facilities. IATSS Research. 2016;40(1):26-34.

4. Punyakaew A, Lersilp S, Putthinoi S. Active Ageing Level and Time Use of Elderly Persons in a Thai Suburban Community. Occupational Therapy International. 2019;2019:1-8.

5. Ansari AK, Akhund IA, Shaikh AQ. Stroke in elderly; identification of risk factors. J Ayub Med Coll Abbottabad. 2001 Jul-Sep;13(3):11-3.

6. Murakami K, Asayama K, Satoh M, Inoue R, Tsubota-Utsugi M, Hosaka M et al. Risk Factors for Stroke among Young-Old and Old-Old Community-Dwelling Adults in Japan: The Ohasama Study. Journal of Atherosclerosis and Thrombosis. 2017;24(3):290-300.

7. Engstad, T., Engstad, T.T., Viitanen, M. and Ellekjær, H. 2012. Epidemiology of stroke in the elderly in the Nordic countries. Incidence, survival, prevalence and risk factors. Norsk Epidemiologi. 22, 2 (Nov. 2012).

8. Long X, Lou Y, Gu H, Guo X, Wang T, Zhu Y et al. Mortality, Recurrence, and Dependency Rates Are Higher after Acute Ischemic Stroke in Elderly Patients with Diabetes Compared to Younger Patients. Frontiers in Aging Neuroscience. 2016;8. 
9. Kammersgaard L. P., Jørgensen H. S., Reith J., Nakayama H., Pedersen P. M., Olsen T. S. (2004). Short- and long-term prognosis for very old stroke patients: the Copenhagen Stroke Study. Age. Ageing 33 149-154. 10.1093/ageing/afh052

10. Phrommintikul A. , Detnuntarat P. , Prasertwitayakij N. , Wongcharoen W. Prevalence of atrial fibrillation in Thai elderly. Journal of Geriatric Cardiology (2016) 13: 270-273.

11. Kongbunkiat K, Kasemsap N, Thepsuthammarat K, Tiamkao S, Sawanyawisuth K. National data on stroke outcomes in Thailand. Journal of Clinical Neuroscience. 2015;22(3):493-497.Mayo NE, Nadeau L, Daskalopoulou SS, Cote R. The evolution of stroke in Quebec: a 15-year perspective. Neurology. 2007; 68: 1122-1127.

12. Béjot $Y$, Bailly $H$, Graber M, Garnier L, Laville A, Dubourget L et al. Impact of the Ageing Population on the Burden of Stroke: The Dijon Stroke Registry. Neuroepidemiology. 2019;52(1-2):78-85.

13. Zhao Y, Zou C, Wang C, Zhang Y, Wang S. Long-Term Outcomes after Stroke in Elderly Patients with Atrial Fibrillation: A Hospital-Based Follow-Up Study in China. Frontiers in Aging Neuroscience. 2016;

14. Ruiz-Sandoval JL, Cantú-Brito C, Chiquete E, et al. Acute ischemic stroke in patients older than 75 years in the first decade of 21st century in Mexico. Rev Mex Neuroci. 2017;18(1):42-53.

15. Xia X, Yue W, Chao B, Li M, Cao L, Wang L, et al. Prevalence and risk factors of stroke in the elderly in Northern China: data from the National Stroke Screening Survey [Internet]. Journal of neurology. Springer Berlin Heidelberg; 2019.

16. Venketasubramanian N, Yoon BW, Pandian J, Navarro JC. Stroke Epidemiology in South, East, and South-East Asia: A Review. Journal of Stroke. 2018;20(1):142-.

17. .Kodani E, Atarashi H. Prevalence of atrial fibrillation in Asia and the world. Journal of Arrhythmia. 2012;28(6):330-337.

18. Chei C, Raman P, Ching C, Yin Z, Shi X, Zeng Y et al. Prevalence and Risk Factors of Atrial Fibrillation in Chinese Elderly. Chinese Medical Journal. 2015;128(18):2426-2432.

19. Altieri M. Spase-l: a multicenter observational study on pharmacological treatment of acute stroke in the elderly. The Italian Study of Pharmacological Treatment of Acute Stroke in the Elderly Group. Neurol Sci. 2002; 23: 23-28.

20. International Ethical Guidelines for Health-related Research Involving Humans, Fourth Edition. Geneva. Council for International Organizations of Medical Sciences (CIOMS); 2016 